\title{
2020 AIR FORCE MISSION CAPABILITIES PACKAGES FROM OPERATIONAL ANALYSIS PERSPECTIVE ${ }^{1}$
}

\author{
Velizar SHALAMANOV
}

\begin{abstract}
This article deals with the development of Air Force mission capabilities packages. To this end, it addresses the challenge of operational analysis of the complex relationships among end users, services, missions and tasks of the Air Force, capabilities, resources, units, etc. The author emphasizes the importance of creating respective service-oriented governmental architecture. The need for definition of Universal Task List (UTL) for the whole security sector and distribution of capabilities among security sector organizations is also outlined. A systematic operational analysis for capabilities/force structure planning and mission capabilities packages (MCP) planning for certain operations/services is thoroughly presented.
\end{abstract}

Keywords: Force planning, air force capabilities, task list, air force technologies, operations research, balanced scorecard, QPR.

\section{Introduction: Mission and Universal Tasks of Bulgarian Air Force}

The Bulgarian Air Force (AF) has clear mission to provide Air Sovereignty (air policing, air defense, control of the airspace) and air support to Land Forces and the Navy, as well as to play crucial role with airlift capabilities, reconnaissance, search and rescue, evacuation, fire-fighting, and other support activities. Training and certification is another important mission.

Certainly, there are some invariant missions such as radar coverage with IFF capability to provide common recognized air picture. Command and control with adequate Air Operations Center / Air Sovereignty Operations Center (AOC / ASOC) is critical to the integration of air power. Communications, including at present predominantly data links (for example, Link 16), are essential for any other mission as well as for the integration of the AF with other services and allies in a network-enabled force. The need for a coalition-wide planning is crucial for a country that is NATO and also EU member. 
For future force development the end user becomes more and more important, that is we have a shift from enemy centric planning to capabilities centric approach and finally to user-oriented planning model. The analysis of the services provided to the end user leads to the Universal Task List (UTL) for the AF, from which required capabilities could be drafted. This creates a complex network of a user, services, UTL, capabilities, resources, units, etc. The operational analysis of such a complex system is the challenge addressed in this paper.

Certainly, some of the above mentioned AF missions and respective capabilities could be assigned to other institutions, but this is something to be decided after a serious operational analysis of the specific case of Bulgaria. There is a clear and present need to develop a service-oriented governmental architecture in the field of aviation. ${ }^{2}$ After that it will be possible to define alternatives for the organizational support of these services and to select the best option. It is more or less evident that in a small country like Bulgaria it is difficult to expect the government to have many air-related service operators. Different services could be used by different agencies and other users, but operator could be one body (or several bodies with certain specialization horizontally or vertically, but without overlap and duplication).

The main themes in this article are:

- The importance of the service-oriented governmental architecture in the aviation field;

- The need for security sector large UTL definition and distribution of capabilities;

- The crucial role of IFF and data link for network enabled forces;

- The need for a systematic operational analysis for capabilities/ force structure planning and mission capabilities packages (MCP) planning for certain operations/ services;

- The role of the Center of Excellence in Operational Analysis (CoE-OA) and the supported by the Center Joint Training Simulation and Analysis Center (JTSAC) for Computer Assisted Exercises (CAX) to provide Concept Development and Experimentation (CDE) followed by Implementation Planning, Management and Measurement (IPMM) using Balanced Scorecards (BSC).

\section{Services Provided and Capabilities Supported by the Air Force}

The definition of capabilities and services provided by the AF is essential part of the planning process. This is an iterative process comprising several steps:

- Initial definition services, required UTL and capabilities needed for these AF UTL; 


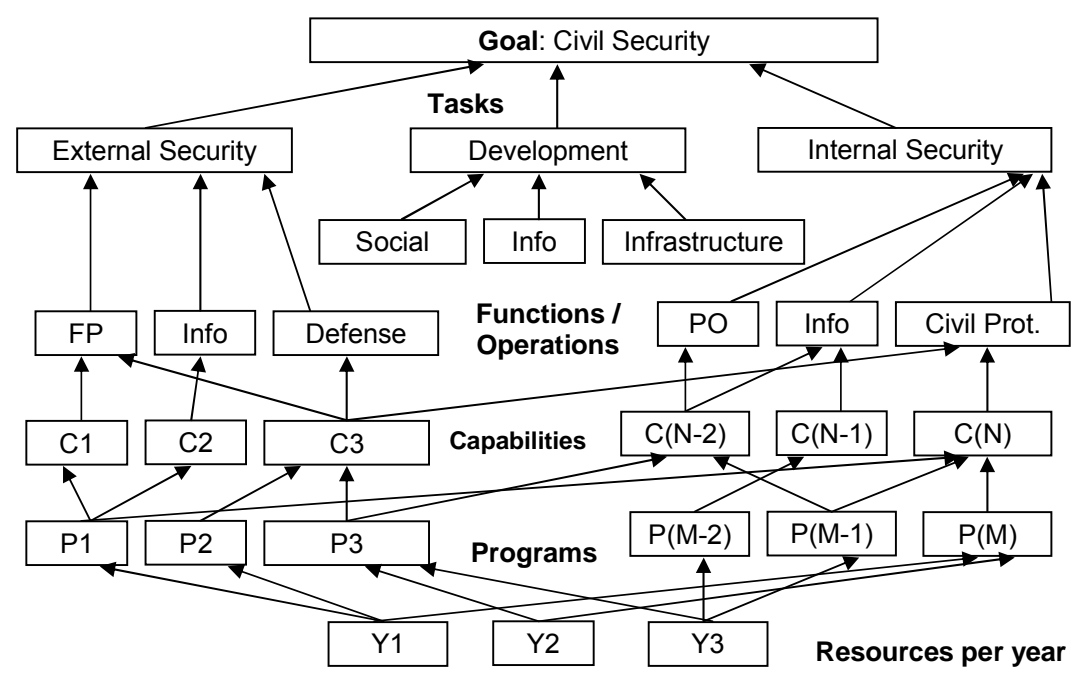

Figure 1: AF Capabilities as Element of the Security Sector Capabilities.

- Integration and balancing with the capabilities and services of other institutions;

- Development of a Mission Capabilities Packages planning system for specific operations/ services.

When considered at Alliance level, the process of operational analysis has to include coordination and balancing on international level as well.

Another specific aspect is related to the possibility of one mission being carried out with different set of capabilities and a certain capability to be built trough different programs (with different type of equipment, personnel, training, logistics, doctrine, etc.). At the end, all programs are funded practically from one budget for security and defense.

The real challenge is to optimize the set of programs in such way that with minimum budget to provide the best combination of capabilities in different institutions (including AF) and related services that through different operations/ functions contribute to the main goal of security - protection and freedom of the citizens (the ultimate end-user).

Figure 1 illustrates the procedure used to generate a set of analysis/ optimization modules for decision-making support aiming to find the best possible way to distrib- 
ute a limited amount of money to different programs in order to obtain the best mixture of capabilities in different institutions for the most effective joint/ coalition operations. This approach is being further developed in the CoE-OA, but in a more efficient way this task could be solved if Bulgaria requests transfer of capabilities planning/ change management models from the NATO C3 Agency and tries to participate more actively from the very beginning in the research plans of the newly established European Defense Agency.

The definition of distribution of services and capabilities among different institutions relates mainly to procurement and maintenance of equipment, training of personnel and provision of certain level of readiness. This is essentially definition of a serviceoriented governmental architecture. The next challenging task is planning and operational use of mission capabilities packages for real operations - providing real services.

\section{Alternatives for Mission Capabilities Packages}

There are some critical capabilities_invariant to any service-provided by the AF as, for example:

- Collection of common recognized air picture (including IFF);

- Adequate command and control (C2);

- Modern data links and other type of communications (Comms);

- Decision-making support tools (DSS).

These are network-enabled capabilities (NEC) for the AF on national level and in coalition environment.

Other important capabilities, which directly produce service for the end user, are:

- Air defense and air superiority;

- Air support/ strike;

- Transport - operational/ tactical airlift;

- Reconnaissance;

- Search and rescue;

- Emergency management support;

- Training.

It is important to decide on the list of possible MCP and variations for their services. As a next step for every MCP, the pool of equipment and personnel has to be identified (developed/ trained). There are different options and the clear definition of these 
options as well as the criteria for assessment and selection are important elements in the decision-making process.

So, there are alternatives for the pools of capabilities from which we could develop alternatives for MCP in preparation of specific operation. ${ }^{3}$

When developing the alternatives for the pools of capabilities for generation of certain MCP, we have to keep in mind the range of MCP we plan to build for typical operations, as well as how many MCP will be deployed simultaneously.

It is realistic to consider as a first option the possibility to maintain pools of capabilities for all eleven MCP listed above. These pools will be the main organizational formations of the $\mathrm{AF}$, for example:

- Multi-role fighter unit;

- SAM unit;

- Combat helicopters unit;

- $\quad$ Reconnaissance unit (UAV or other);

- Transport airplanes unit;

- Transport helicopters unit;

- Radar unit;

- C2 unit;

- Communications unit;

- Logistics unit;

- Training unit.

Every MCP will need capabilities from different pools integrated and focused on the result/ effect - following the effect-based operations concept. Every MCP will certainly need C4ISR (including IFF) capability to integrate all other capabilities for combat result/ effect as well as logistics to sustain itself. In most of the cases MCP are for expeditionary missions so they will need reach-back and air lift.

Some of the above mentioned units providing the pool of forces for MCP could be integrated (for example, helicopter units). Some of these pools could be used to plan MCP for other services/ institutions - if for example all helicopters are in the AF, from these helicopters MCP for the Ministry of Interior or the Ministry of Emergency Management could be formed.

Some of the MCP for a certain operation will probably require capabilities that are provided by pools of capabilities developed in other institutions- for example, communications, radars, transport vehicles/ aircrafts, etc. 
In the CoE-OA, tools are under development to analyze the needed MCP for future missions, but the real use of these software packages will require close cooperation with military experts. Algorithms are available for generation of alternatives for MCP according to defined mission (combat effect/ result) from available pools of capabilities in different units. The service-oriented architectural approach forms the basis for definition of alternatives for MCP (operations planning) and before that - capabilities pools (force planning).

\section{Assessment and Selection of MCP}

When we consider a specific operation, the set of MCP has to be defined and configured from the existing building blocks. For example, a set of MCP that are needed for Kabul airport control in Afghanistan or to support the Bulgarian participation in Iraq, Kosovo, or Bosnia, could be defined having in mind the services to be provided there and the availability of capabilities in different units (including level of interoperability and readiness, sustainability in the context of the real operation).

As an example, for all expeditionary operations we need MCP for operational airlift, as well as MCP for local air transport/ tactical airlift, evacuation, and SAR. In addition, in any expeditionary operation there is a need for air reconnaissance and, in certain cases, close air support. Obviously, field Air Operations Center is needed for any deployed air capability as well as local radar coverage and certainly IFF capability for all aircrafts.

For every specific case, there are many alternatives for the MCP composition from existing pools of items, so there is a need for decision-making support in forming different MCP, assessing them and selecting the best alternative. Selecting one alternative as a result of comparative assessment is rather easier than trying to generate optimal MCP, or to pretend that there is one and only option for the required MCP. In the CoE-OA, there is expertise in using the software Expert Choice/ Multi-Choice 2 for generation of alternatives, assessment, and selection. As a separate first step, the overall architecture of the AF or possible typical MCP could be developed using System Architect. ${ }^{4}$

Sometimes, it is impossible to optimize the force architecture as a whole without considering all MCP together and in the context of possible planning scenarios. For example, MCP for Air Defense (AD) and MCP for Air Support (AS) as well as other possibilities could be generated from different elements - AD from mix of specialized AD fighters and surface-to-air missile (SAM) complexes, AS from strike fighters and helicopters as well as missiles, but both AD and AS MCP could be formed from multi-role fighters with more flexibility and with lower cost of overall life-cycle support. 
Operational analysis based on generation and assessment of alternatives with selection of the optimal one is a key instrument for force planning, capabilities planning, and MCP planning in a complex.

The link between MCP planning and force structure (pools of capabilities) planning is very sensitive in the real time/ resource/ information-uncertainty frame. For example, a planner could decide to keep and modernize in certain way older equipment until more resources/ information is acquired for a new procurement. It is even possible to plan modernization in such a way that provides for security of investment in certain critical capabilities as communications, data links, IFF, etc.

Let us consider three options for MCP-AD: Bulgaria could keep MiG-29 for another 15 years, upgrading them with data link and IFF; could acquire second-hand F-16 with the same data link/ IFF capability for the next 15 years; and could procure new Grippen for the next 30 years. In the first two cases, Bulgaria will save money and will be prepared after 15 years with more resources and information to acquire a modern multi-role fighter for the next 40 years. In the first case, the initial price is lower than in the second case, but the transition from MiG-29 to a new multi-role fighter after 15 yeas will be more difficult and the exploitation cost will be higher. In the third case, the price is in the middle, but the risk of uncertainty is higher. All options could be assessed according to selected criteria and focused on certain goal, which will provide a solid ground for a decision to be taken. This could be achieved only through comprehensive operational analysis process. Such a process could not be separated from the developments in our NATO neighbors; further, it needs to account for the current and planned US military presence in Southeast Europe. ${ }^{5}$

\section{Result-Oriented Implementation Management}

In order to have effective management of the development of pools of capabilities as well as formation/ generation of MCP for certain operations, there is a need for a management system oriented towards a balanced system of indicators/ scorecards (BSC). ${ }^{6}$

Implementation management has to be realistic from resource point of view, priority of needed MCP for operations we are committed to, and according to the timetable of achieving required level of readiness.

It means that there is a need for combination of several parallel processes in one transformation process, in addition to which real deployment for operations is essential. The management of this combination of processes is a complex task because they are of different nature and normally with multi-source funding (national funds, public-private partnership or private financing initiatives, foreign military financing, 
NATO/ EU funding) and reporting to different institutions (not only to those who fund the projects, but to stakeholders in the society).

For example, the processes are at least of three different types:

- Management of an organizational unit (capability pool or production unit);

- Management of a project - procurement/ modernization or utilization process;

- Management of current operation of deployed forces.

The sources of funding are from national defense budget, international programs (NATO, EU), bilateral foreign military funding, loans, national infrastructure project funding (for example air and maritime security, including IFF) and have different rules of spending.

In the CoE-OA there is a tool based on Microsoft Project and QPR ScoreCard ${ }^{7}$ to support such complex change management processes of different type of sub-processes with different lines of funding and reporting.

\section{Role of the Center of Excellence in Operational Analysis}

The CoE-OA is a specialized academic body with core competences in the area of operations research and computer assisted exercises (based on modeling and simulation) that works with experts from military staff and administration to develop options, analyze these options, assess them, and recommend solutions to various problems in the fields of operational planning, capabilities planning, acquisition management, etc. In the environment described above, the CoE-OA is able to define in an interactive and iterative way a concrete structure for the scheme presented in Figure 1 and later to define options for pools of capabilities, structure of key MCP as well as plan for development and maintenance of these pools and MCP.

The most simplistic approach is to have a phase space for the AF with a step of one year (year budget) or three years (budget forecast) with assessment of static maintenance expenditures (including resources for operations) and dynamic expenditures (change/ investment - including training of personnel and organizational restructuring that is related to utilization of extra equipment as well) from phase to phase.

Let us consider an example based on the data given in Table 1 with the following capability pools/ units with certain number of items and cost of procurement and operational deployment: 
Table 1: Generation of MCP from Capabilities Pools (CP) with Assessment of Cost for Maintenance of CP and Use of MCP for Certain Operation.

\begin{tabular}{|c|c|c|c|c|c|c|c|c|c|}
\hline Operation & MCP 1 & MCP 2 & MCP 3 & MCP 4 & MCP 5 & Need & Cost & proc & ops \\
\hline CP 1 & 1 & 1 & 5 & 1 & 1 & 6 & 60 & 10 & 0,5 \\
\hline CP 2 & 1 & 1 & 6 & 1 & 1 & 7 & 7 & 1 & 0,2 \\
\hline CP 3 & & & 6 & & & 6 & 120 & 20 & 1 \\
\hline CP 4 & 3 & 4 & & & 2 & 6 & 60 & 10 & 1 \\
\hline CP 5 & & 4 & & 6 & & 6 & 90 & 15 & 1 \\
\hline CP 6 & 1 & 1 & 3 & 1 & 1 & 4 & 8 & 2 & 1 \\
\hline CP 7 & 1 & 1 & 3 & 1 & 1 & 4 & 8 & 2 & 0,5 \\
\hline Cost & 5,2 & 10,2 & 14,2 & 8,2 & 4,2 & $\mathbf{2 8 , 4}$ & $\mathbf{3 5 3}$ & & \\
\hline
\end{tabular}

- $\quad \mathrm{CP} 1$ - radar unit (1 item is $10 \mathrm{M}$ for procurement and $0.5 \mathrm{M}$ for 6 months operation with deployment/ redeployment);

- $\quad \mathrm{CP} 2$ - communications unit (1 item is $1 \mathrm{M}$ for procurement and $0.2 \mathrm{M}$ for 6 months operation with deployment/ redeployment);

- $\quad$ CP3 - fighter unit (1 item is $20 \mathrm{M}$ for procurement and $1 \mathrm{M}$ for 6 months operation with deployment/ redeployment);

- CP4 - air transport unit (1 item is $10 \mathrm{M}$ for procurement and $1 \mathrm{M}$ for 6 months operation with deployment/ redeployment);

- $\quad$ CP5 - air support unit (1 item is $15 \mathrm{M}$ for procurement and $1 \mathrm{M}$ for 6 months operation with deployment/ redeployment);

- CP6 - logistics unit (1 item is $2 \mathrm{M}$ for procurement and $1 \mathrm{M}$ for 6 months operation with deployment/ redeployment);

- $\quad$ CP7 - C2 unit (1 item is $2 \mathrm{M}$ for procurement and 0.5 $\mathrm{M}$ for 6 months operation with deployment/ redeployment).

Total cost for procurement will be 353 Million.

In Table 1, we consider the following MCP with the presumption that only one MCP will be deployed at a time and certain reserve to define the number of needed items in every unit:

- $\quad$ MCP1 - operational air lift;

- $\quad$ MCP2 - tactical air lift;

- $\quad$ MCP3 - air sovereignty; 


\section{Phase Diagram of AF Development to 2020}

\begin{tabular}{|l|l|l|l|l|}
\hline $\begin{array}{l}\text { Years } \\
\text { budget }\end{array}$ & $\begin{array}{l}2007-2009 \\
130 \mathrm{M}\end{array}$ & $\begin{array}{l}2010-2012 \\
150 \mathrm{M}\end{array}$ & $\begin{array}{l}2013-2015 \\
170 \mathrm{M}\end{array}$ & $\begin{array}{l}2015-2020 \\
190 \mathrm{M}\end{array}$ \\
\hline $\begin{array}{l}\text { CP } \\
\text { Procure } \\
\text { Sustain }\end{array}$ & $\begin{array}{l}\mathrm{CPi}-30 \% \\
40 \mathrm{M}\end{array}$ & $\mathrm{CPi}-50 \%$ & $\mathrm{CPi}-70 \%$ & $\mathrm{CPi}-70 \%$ \\
\hline $\begin{array}{l}\text { MCP } \\
\text { readiness }\end{array}$ & $\begin{array}{l}\mathrm{MCPk}-60 \% \\
10 \mathrm{M}\end{array}$ & $\begin{array}{l}\mathrm{MCPk}- \\
100 \%\end{array}$ & $\mathrm{MCPj}-70 \%$ & $\begin{array}{l}\mathrm{MCPj}- \\
100 \%\end{array}$ \\
\hline $\begin{array}{l}\text { MCP } \\
\text { deployed }\end{array}$ & $\begin{array}{l}\mathrm{MCPs} \\
30 \mathrm{M}\end{array}$ & $\mathrm{MCPk}$ & $\mathrm{MCPr}$ & $\mathrm{MCPj}$ \\
\hline
\end{tabular}

Figure 2: Change Management Table.

- $\quad$ MCP4 - air support;

- $\mathrm{MCP} 5$ - SAR/ emergency support.

Total cost for critical deployment in this case will be 28.4 Million.

The change management table shown in Figure 2 defines only one route - real operational analysis has to be based on a network diagram with many different options for every time period and transition arrows with certain cost. Practically, all these states in the diagram are concrete realization of the BSC to measure the effectiveness of AF transformation and the goal of planning is to define the optimal trajectory of the transformation as well as to manage it in the best possible way.

For the diagram, there are some critical steps to be taken:

1. Definition of goals for the next $10-15$ years;

2. Definition of future capabilities;

3. Development of planning scenarios and level of ambition;

4. Concept development;

5. Planning/ costing of experimentation, including exercises;

6. Lessons learned;

7. Planning/ costing of implementation of concepts;

8. Planning/ costing of education, training and certification; 
9. Planning/ costing for real deployment with subsequent lessons learned, improving of concept implementation and feedback to education/ training.

In such a network of phase situations we could identify the best end state in 10-15 years period and the best trajectory to reach it according to a set of criteria, including available resources.

In the course of such a planning process, criteria for success are identified that could lead to a balanced scorecard for transformation effectiveness.

\section{Conclusions and Recommendations}

A clear definition is needed for the main AF services, the respective UTL and the key required capabilities in order to define pools of capabilities and mechanism what is the possible optimal way to form MCP for a certain operation according to planning scenarios. $^{8}$

Some other security-related services (for example, provided by the Ministry of Interior or the Ministry of Emergency Management, even by the other branches in the Ministry of Defense) require the same or similar capabilities available in the pools of capabilities of the AF. This calls for integrated capabilities planning for pools as well as integrated MCP planning for certain operations across the services and ministries.

The best way to develop methodology and supporting software is to test these concepts through series of exercises (preferably CAX) with the participation of many institutions in order to identify all the criteria and options/ alternatives for optimal/ rational decision-making. ${ }^{9}$

The main idea of this article is to stress the need of cooperation in the development of capabilities model of the AF in balance with other services and institutions outside MoD in order to optimize the pools of capabilities supported by the AF and the process of MCP planning for specific operations on national and NATO or EU level.

The main conclusion specific for the AF is that an IFF/ Data Link solution has critical importance and has to be flexible enough to integrate every element of the AF Architecture in the process of change of platforms/ weapons in the NEC force. The proposed solution is based on a tailored package for different air platforms and radar sites and maintenance of commonly supported integration architecture.

An additional conclusion is related to the integrated planning of transport/ SAR/ emergency support/ crisis management support capabilities at large with the other institutions in the security sector. It is most important currently in the area of transport airplanes/ transport helicopters and their specific capabilities as well as common field AOC for joint/ combined operations. What the CoE-OA proposes in this sense is 
based on integrated capabilities/ MCP planning system and flexible field C2 modules to establish mobile AOC for different operations.

The general process of MCP planning through support of Concept Development and Experimentation using CAX in the area of civil-military cooperation in crisis management is supported by the NATO SfP981149 Project for capacity building in the CoE-OA. The key tools used in the CoE-OA are System Architect/ OpNet for architecture development, SCIP/ Powersim for scenario planning and simulation in decision-making support, a set of analysis/ optimization models and MS-Project/ QPR ScoreCard for management of the process, together with an environment for CAX to support analysis and decision-making with experts in the loop.

Finally, it has to be recognized that effective AF MCP planning is impossible outside the collective capabilities planning in NATO and EU as well as without close cooperation with our neighbors, especially Romania as a new NATO/ EU ${ }^{10}$ member and also considering the future membership of Macedonia and Albania. The Bulgarian NATO/ EU commitment to Black Sea Cooperation ${ }^{11}$ and especially the role for integration of Georgia has to be kept in mind during the planning process.

In this context, the CoE-OA and the Joint Training, Simulation and Analysis Center (JTSAC), developed by the Institute for Parallel Processing, Bulgarian Academy of Sciences, in cooperation with other institutes to support the transformation of the security sector are examples for the approach we propose to the AF as well as to other services from the national security sector. Such an approach will facilitate the transformation to an integrated security sector with cooperation between services, industry, and academia. ${ }^{12}$

Now, when main platforms - transport/ training airplanes and helicopters-are procured as well as airfield modernization has been finished at high enough cost with forecast for large funding not so favorable in the future, the challenge to the AF is the development of service-oriented architecture and the establishment of MCP/ force structure planning and management system in the context of the whole security sector and even of NATO/ EU as well as of a regional scope. 


\section{Notes:}

1 This publication is supported by the NATO's Scientific Division in the framework of the Science for Peace Program - Project SFP-981149 (2005-2007) and contributes to the National Fund “Scientific Research" Project VU-1037/2005 of the Center for National Security and Defense Research.

2 Dirk Krafzig, Karl Banke, and Dirk Slama, Enterprise Service Oriented Architecture Best Practices (Prentice Hall - PTR, 2005).

3 Daniel Hamilton, ed., Transatlantic Transformations: Equipping NATO for the $21^{\text {st }}$ Century (Washington, D.C.: Center for Transatlantic Relations, 2004).

4 <http://www.telelogic.com/index.cfm> (21 May 2007).

5 US Realignment and NATO Transformation: Implication for Southeast Europe and Greater Black Sea Area (Bucharest, 2005), 208 p.

6 Robert Kaplan and David Norton, The Balanced Scorecard: Translating Strategy into Action (Harvard Business Scholl Press, 1996).

7 <http://www.qpr.com/Solutions/Balanced_Scorecard/index.html> (22 May 2007).

8 Hans Binnedijk, ed., Transforming America's Military (Washington, US National Defense University, Center for Technology and NS Policy, 2002).

9 Velizar Shalamanov, “Concept Development and Experimentation: Academic Support to Security Sector Transformation” (paper presented at the SMi NATO Enlargement Conference, 16-17 November 2005, Sofia, Bulgaria).

10 Southeast European Security after the 2004 Dual Enlargement (Bucharest, 2003).

${ }^{11}$ Strengthening Black Sea Security (Sofia, 1-3 November, 2005).

${ }^{12}$ Velizar Shalamanov, "C4ISR in Navy Transformation: Role, Joint Research and Advanced Technology Demonstrations,” Information \& Security: An International Journal 13 (2004): 35-50.

VELIZAR SHALAMANOV is Senior Research Fellow and Head of the C4 section of the Institute for Parallel Processing of the Bulgarian Academy of Sciences. He is Chairman of “George C. Marshall”-Bulgaria. From November 1998 till July 2001 Dr. Shalamanov was Deputy Minister of Defense, responsible for defense policy and planning. He has more than 150 publications in the areas of CIS architecture and development, information warfare, decision support, national and regional security policy, defense planning and reengineering. Dr. Shalamanov is co-founder of the AFCEA-Sofia Chapter and the Business Executives for National Security - Bulgaria. He serves on the International Advisory Board of DCAF. E-mail: Shalamanov@GCMarshall.bg. 